\title{
Analysis of the 3-Glycidoxypropyltrimethoxysilane (GPTMS) hydrolysis by infrared spectroscopy
}

\author{
Cézar Augusto Casagrande ${ }^{1,2}$, Lidiane Fernanda Jochem ${ }^{3}$,
} Wellington Longuini Repette ${ }^{1}$

\author{
${ }^{1}$ NanotecLab - Department of Civil Engineering (ECV), Federal University of Santa Catarina (UFSC), Street João Pio \\ Duarte s/n, CEP: 88040-900, Florianópolis, SC, Brasil. \\ ${ }^{2}$ Federal University of Pernambuco, Technologic Nuclei of Campus Agreste (NT-CAA), Av. Campina Grande, s/n - Km 59, \\ Nova Caruaru, CEP: 55014-900, Caruaru, PE, Brasil. \\ ${ }^{3}$ Federal Technological University of Paraná (UTFPR), Civil Construction Academic Department (DACOC), Campus \\ Ecoville, Street Deputado Heitor Alencar Furtado, 5000, CEP: 81280-340, Curitiba, PR, Brasil. \\ e-mail: cezar.acasa@gmail.com, lidijochem@gmail.com,wellington.repette@gmail.com;
}

\begin{abstract}
The study of silanes and polymers with special functions is increasing and the development of materials from silane-based polymers follows this trend. In this way, the hydrolysis of 3-Glycidoxypropyltrimethoxysilane (GPTMS) was studied as a function of the hydrolysis time in solutions with $50 \%$ of alcoholic solvents by infrared spectroscopy. It was verified that it was possible to analyze qualitatively and quantitatively the chemical reactions involving the hydrolysis / condensation of GPTMS and the main kinetics variations during the process. The results suggest that up to 30 minutes of hydrolysis, the predominant reactions are hydrolysis of the alkoxy groups, with the generation of the Si-OH groups and alcohol, in this case methanol. From 30 minutes, there is a large amount of silanols in the solution that tend to condense and form siloxane groups, which has this reaction accelerated from 60 minutes. Already, from 70-80 minutes, the reactions tend to decrease the kinetics, due to the absence of silanols and the hydrolysis / condensation process.
\end{abstract}

Keywords: GPTMS, hydrolysis, infrared spectroscopy, silane

\section{INTRODUCTION}

The utilization of metallic precursors for sol-gel systems production have been explored with more attention since the 50's with the main objective of the formation of three-dimensional inorganic networks [1,2]. Predominantly, the most commonly used material for carrying out the sol-gel process are the alkoxysilanes. Metallic alkoxides are chemical compounds with general formula $\mathrm{Me}(\mathrm{OR})_{\mathrm{n}}$ where "Me" is the metal and " $\mathrm{R}$ " is an alkyl group (methane, ethane, butane, etc., $\mathrm{CH}_{3}, \mathrm{C}_{2} \mathrm{H}_{5}$, $\mathrm{C}_{4} \mathrm{H}_{7}$, etc, respectively) subject to hydrolysis and polycondensation process in the presence of some catalyst and water [3]. In this perspective, the sol-gel process with metal alkoxides becomes possible to synthesize a multitude of materials, as high technology engineering materials such as thin films, dispersed particles, aerogels, protective agents and additives for ceramic materials, metallic or polymeric [4 - 10].

Alkoxysilanes are chemical compounds with molecules based on the silicon atom as the main element and that, in the majority of molecules, present two types of chemical interaction, present in it extremities, being one inorganic and the other organic. They are generally referred by the hydrolysable group, the alkoxy type, and an organofunctional group (amine $\left(-\mathrm{NH}_{2}\right)$, vinyl $(-\mathrm{C}=\mathrm{C})$, etc.). Also, the alkoxy group may occupy the position of the organofunctional group, such as tetraethoxysilane (TEOS) and tetramethoxysilane (TMOS). Among this types of silanes, TEOS is the most used [2, 11]. Basically, when the silane comes in contact with water, the alkoxy groups start to hydrolyze, resulting in silanol (Si-OH) groups and by-products of the hydrolysis which are usually alcohols, commonly of the same composition as the solvent used for the dispersion of the silane, as suggested in Equation 1. These silane groups have potential and are responsible for polycondensation, gel formation and, subsequently, formation of the inorganic three-dimensional network, as suggested in Equation 2. 


$$
\begin{aligned}
& \mathrm{Si}(\mathrm{OR})_{\mathrm{n}}+\mathrm{H}_{2} \mathrm{O} \rightarrow \mathrm{SiOH}(\mathrm{OR})_{\mathrm{n}-1}+\mathrm{ROH} \\
& \mathrm{Si}(\mathrm{OH})_{4}+\mathrm{Si}(\mathrm{OH})_{4} \leftrightarrow \mathrm{Si}_{2} \mathrm{O}(\mathrm{OH})_{6}+\mathrm{H}_{2} \mathrm{O}
\end{aligned}
$$

Although the silane hydrolysis technique is currently employed in several technological systems, the hydrolysis of silanes is, in general, sensitive to various procedure conditions. Also, several variables may interfere with the kinetics of hydrolysis/condensation of silanes. Among them, it can be mentioned the silane type, the $\mathrm{pH}$ of the solution, the reaction temperature, agitation energy and the silane concentration in the solution, which is usually less than $10 \%$ by volume, the amount of hydrolysable grains, among others. Moreover, the amount of solvent used is a determining factor in the reaction kinetics of the silanes. In most studies, the consumption of organic solvent (usually alcohols) is in the order of 80-98\% of the volume of the solution, which causes direct impact on the environment due to volatile organic compounds (VOC's). In this sense, research using hydrolysis processes of silanes with low VOC content shows that with consumption in the $50 \%$ range of organic solvents it is possible to carry out the hydrolysis in an appropriate way $[12,13]$. Hence, this work aims to investigate and monitor, through infrared spectroscopy, the reaction kinetics of the hydrolysis/condensation of GPTMS, catalyzed in acidic medium, as a function of the time of dilution of the silane in solvent-based on methanol.

\section{EXPERIMENTAL PROGRAM}

\subsection{Materials}

3-Glycidoxypropyltrimethoxysilane (GPTMS) was used as reactant and it properties are shown in Table 1. As pH regulator, acetic acid $\left(\mathrm{CH}_{3} \mathrm{COOH}\right)$ with concentration greater than $99 \%$, produced by Aldrich (USA), was used. As the alcohol solvent, methanol $\left(\mathrm{CH}_{3} \mathrm{OH}\right)$ with concentration greater than $96 \%$, produced by Aldrich (USA), was used.

Table 1: GPTMS characteristics

\begin{tabular}{l|l}
\hline Name & 3-Glycidyloxypropyltrimethoxysilane \\
\hline Initials & GPTMS \\
\hline Producer & Gelest (USA) \\
\hline Purity & $>96 \%$ \\
\hline Hydrolysable group & Methoxy \\
\hline Functional group & Epoxy \\
\hline Chemistry formula & $\mathrm{C}_{9} \mathrm{H}_{20} \mathrm{O}_{5} \mathrm{Si}$ \\
\hline Molar mass (g/mol) & 236.34 \\
\hline Structural formula & \\
\hline
\end{tabular}

\subsection{Hydrolysis/condensation monitoring}

For the characterization of infrared spectra, a Jasco FT/IR-4200 spectrometer was used, with an attenuated total reflectance accessory - ATR PRO450-S/470-H (ATR), the accessory have a zinc selenide crystal (ZnSe) (Figure 1 (a)). For each analyzed infrared spectra, 42 scans were performed in the wavenumber range of 4000 to $550 \mathrm{~cm}^{-1}$ and resolution of $0.5 \mathrm{~cm}^{-1}$. For the analysis of the solutions, some drops of the samples were deposited in the sample holder up to cover the entire crystal of the ATR (Figure 1 (b)). All spectra were evaluated with Spectral analysis software, from Jasco. 


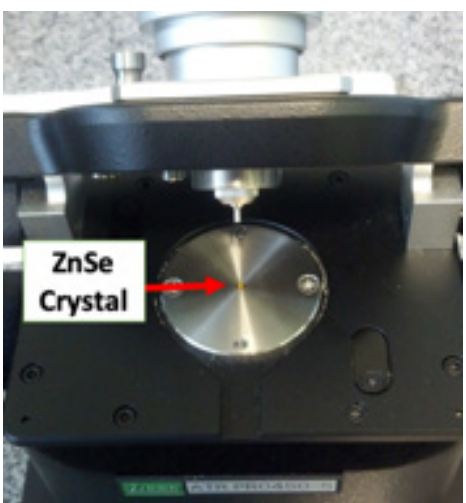

(a)

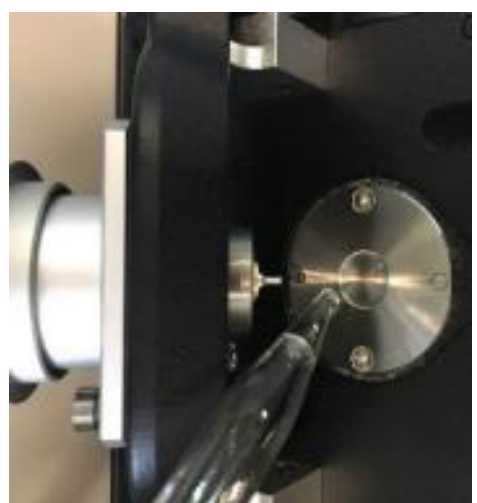

(b)

Figure 1: Equipment for the infrared spectroscopy analysis. (a) Sample compartment in the ATR accessory; (b) Deposition of the liquid sample covering the crystal of the ATR.

For the dilution of the GPTMS, an alcoholic solution formed by methanol and distilled water in the ratio of 1: 1 (by volume), acidified with acetic acid until pH stabilization of $5 \pm 0.2$ was used (called as "methanoic solvent"). For the analysis of the GPTMS hydrolysis, the characterization of the chemical reagents and the acidified methanoic solvent by infrared spectroscopy was carried out.

Similar to an earlier study [12], in order to monitor the hydrolysis of GPTMS in the concentration solution on the order of $1 \%$ (as most searches) with the equipment at the disposal, a comparative analysis of the infrared spectra of the concentrated GPTMS and the dilutions of $1 \%$ and $10 \%$ (by volume) were performed, according to the scheme in the Figure 2. The extraction of aliquots for the analysis in the diluted samples were performed 25 seconds after the GPTMS dilution.

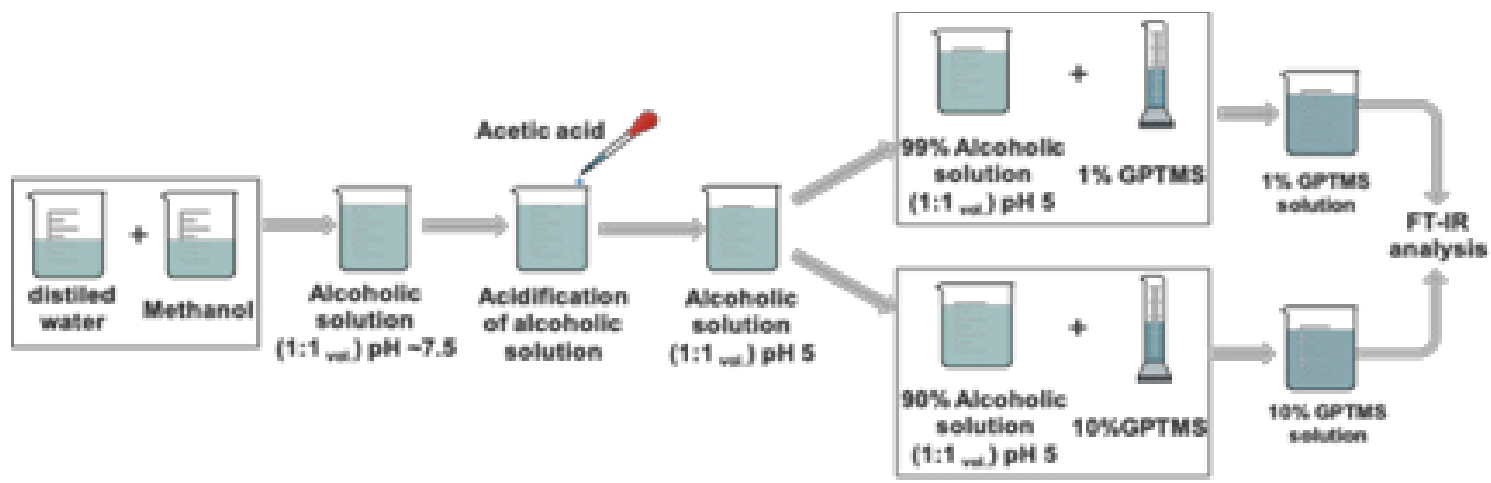

Figure 2: Method of extraction and analysis of the samples by infrared spectroscopy. (a) Analysis of the concentration of GPTMS on the influence of infrared spectra detection;

After determining the appropriate concentration for hydrolysis monitoring (see section 3.1), the hydrolysis monitoring analysis was performed as a function of the GPTMS dilution time. The method consisted in formulating a solution with $90 \%$ (vol.) of acidified alcoholic solution and 10\% (vol.) of GPTMS. The mixture was kept under constant stirring at room temperature $\left(25 \pm 2{ }^{\circ} \mathrm{C}\right)$. From the GPTMS dilution, aliquot extractions of approximately $0.5 \mathrm{ml}$ of the mixture were performed every 10 minutes, for a total period of 120 minutes. From the extraction of the samples until the determination of the infrared spectra in the equipment, it took approximately 40 seconds. The procedures described are illustrated in Figure 3. 


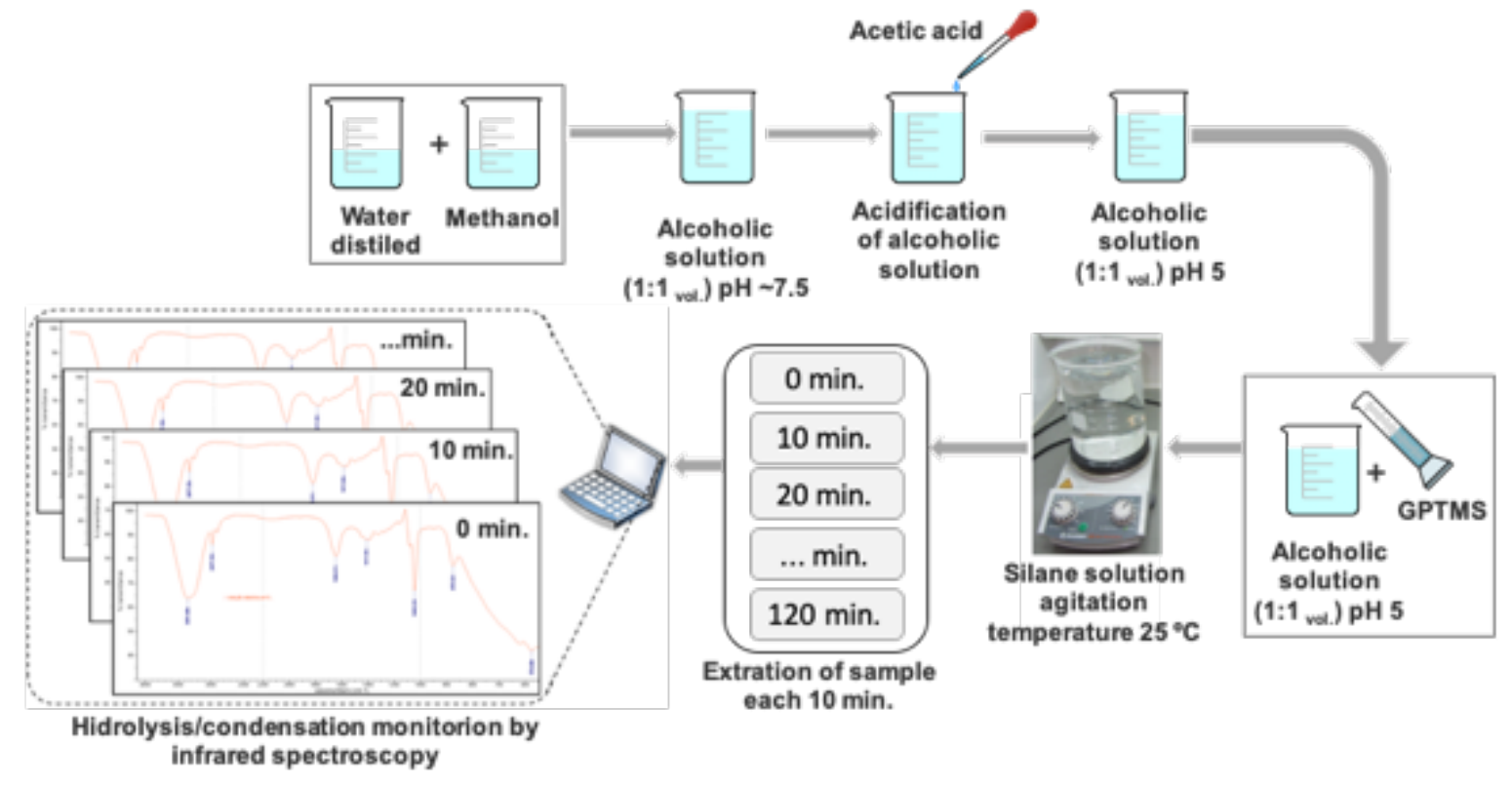

Figure 3: Monitoring analysis of GPTMS hydrolysis as a function of time.

\section{RESULTS AND DISCUSSION}

The results section will be presented in two stages. In the first, the sensitivity of equipment and the characterization of the reagents as also the products and definition of the parameters used for the second stage. In the second stage, the results of GPTMS monitoring study are presented.

\subsection{Sensitivity of equipment and test parameters}

In Figure 4 is presented the infrared spectra of reagents used in the GPTMS hydrolysis study, and in Table 2 the typical chemical bonds identified are listed respectively to the wavenumber of the infrared spectra.

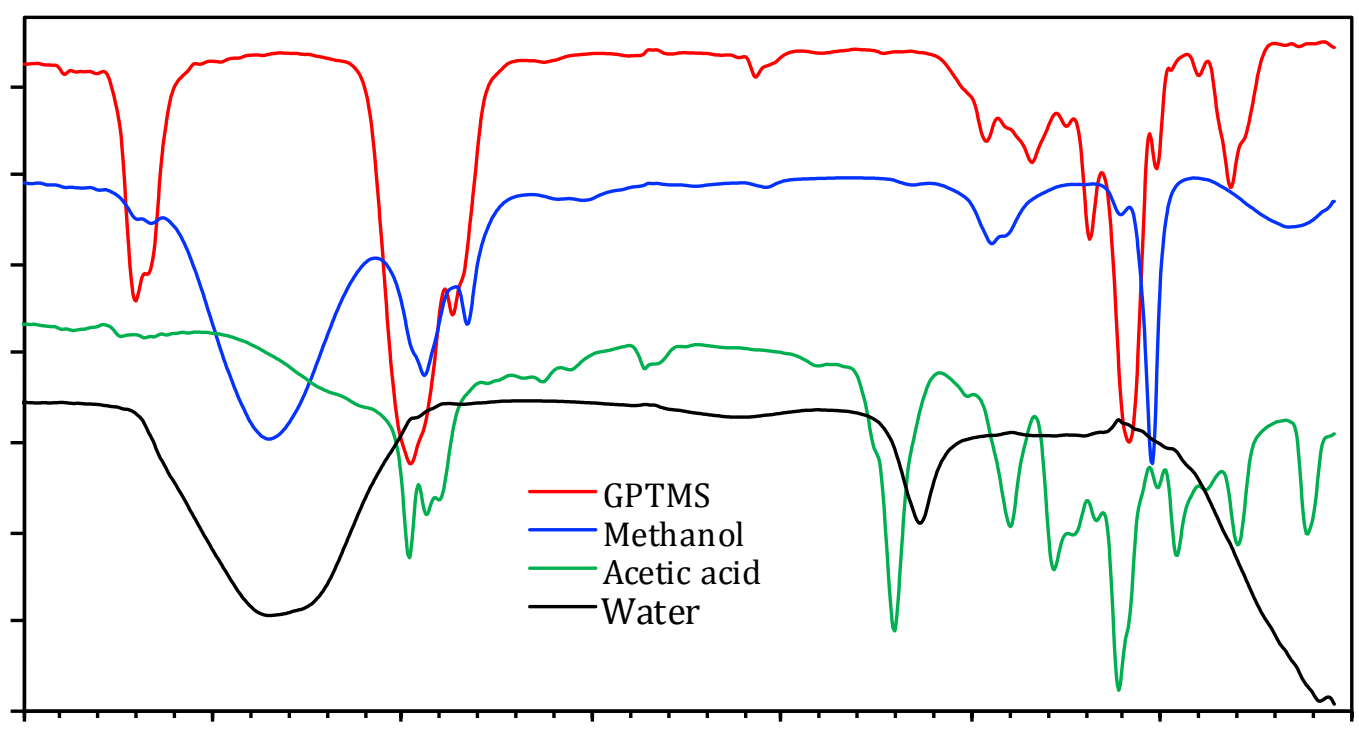

Figure 4: Infrared spectra of the precursors used in this work. 
Table 2: Typical bands of chemical bonds of the reactants [13]

\begin{tabular}{|c|c|c|c|c|}
\hline Wavenumber $\left(\mathrm{cm}^{-1}\right)$ & Water & Methanol & GPTMS & Acetic acid \\
\hline$\cong 3700$ & & & ${ }_{v} \mathrm{Si}-\mathrm{O}(\mathrm{H})$ & \\
\hline $3400-3200$ & ${ }_{v} \mathrm{O}-\mathrm{H}$ & ${ }_{v} \mathrm{O}-\mathrm{H}$ & & \\
\hline $2978-2970$ & & ${ }_{v s} \mathrm{C}-\mathrm{H}$ & ${ }_{v s} \mathrm{C}-\mathrm{H}$ & ${ }_{v s} \mathrm{C}-\mathrm{H}$ \\
\hline $2950-2900$ & & ${ }_{\text {vas }} \mathrm{C}-\mathrm{H}_{3}$ & ${ }_{\text {vas }} \mathrm{C}-\mathrm{H}_{3}$ & vas $\mathrm{C}-\mathrm{H}_{3} / \mathrm{O}-\mathrm{H}$ \\
\hline $1725-1700$ & & & & ${ }_{v} \mathrm{C}=\mathrm{O}$ \\
\hline$\cong 1640$ & ${ }_{\delta} \mathrm{O}-\mathrm{H}$ & & & \\
\hline $1430-1380$ & & ${ }_{8} \mathrm{O}-\mathrm{H}$ & ${ }_{\text {das }} \mathrm{C}-\mathrm{H} / \mathrm{C}-\mathrm{O}$ & ${ }_{\delta} \mathrm{O}-\mathrm{H}$ \\
\hline$\cong 1284$ & & & ${ }_{v s}$ epoxy & ${ }_{\delta}$ asC-O \\
\hline$\cong 1160$ & & & ${ }_{\text {vas }} \mathrm{Si}-\mathrm{O}-\mathrm{C},{ }_{\text {vas }} \mathrm{Si}-\mathrm{O}-\mathrm{Si}$ & \\
\hline$\cong 1114$ & & & & ${ }_{v} \mathrm{C}-\mathrm{O}$ \\
\hline $1080-1070$ & & & ${ }_{\text {vas }} \mathrm{Si}-\mathrm{O}$ & \\
\hline$\cong 1045$ & & ${ }_{v} \mathrm{C}-\mathrm{O}$ & & \\
\hline $960-900$ & & & ${ }_{\delta} \mathrm{Si}-\mathrm{O}(\mathrm{H})$ & ${ }_{v s} \mathrm{C}-\mathrm{H}$ \\
\hline$\cong 879$ & & & vas epoxy & \\
\hline $802-780$ & & & $\begin{array}{l}\underset{v a s}{\mathrm{C}-\mathrm{O}-\mathrm{C},} \\
{ }_{v s} \text { epoxy }\end{array}$ & ${ }_{v} \mathrm{C}-\mathrm{H}$ \\
\hline$\cong 617$ & ${ }_{\delta} \mathrm{O}-\mathrm{H}$ & ${ }_{v i} \mathrm{C}-\mathrm{O}$ & & ${ }_{v} \mathrm{C}-\mathrm{H}$ \\
\hline $580-550$ & ${ }_{v} \mathrm{O}-\mathrm{H}$ & & & \\
\hline
\end{tabular}

v: stretching vibration; vs: symmetrical stretching vibration; vas: antisymmetric vibration; $\delta$ : bending vibration; $\delta$ as: antisymmetric bending vibration.

The transmittance bands in the water infrared spectra are broad, covering majority interest part of infrared spectra in the wavelength range from $4000-3000 \mathrm{~cm}^{-1}, 1800-1500 \mathrm{~cm}^{-1}$ and $1000-500 \mathrm{~cm}^{-1}$ [13]. This makes the analysis difficult because of the large presence of water in the hydrolysis solution (in the order of $50 \%$ by volume). Intensive peaks were detected in the region of $\cong 3350 \mathrm{~cm}^{-1}$ for stretching vibration, $\cong 1640 \mathrm{~cm}^{-1}$ for stretching vibration and a wide peak which progressively increases from $1000 \mathrm{~cm}^{-1}$ to $550 \mathrm{~cm}^{-1}$ for vibrations of elongation and deformation outside the plane, all referring to the $\mathrm{OH}$ bond.

In the methanol, absorption bands were observed in the region of the $\cong 3400 \mathrm{~cm}^{-1}$ infrared spectra related to the hydroxyl stretching vibration of the molecule, in the $\cong 2900 \mathrm{~cm}^{-1}$ region related to the symmetrical and antisymmetric stretching vibration of the $\mathrm{CH}$ groups in the $\cong 1430$ region $\mathrm{cm}^{-1}$ for the hydroxyl bending vibration, in the region of $\cong 1100 \mathrm{~cm}^{-1}$ at $\cong 1000 \mathrm{~cm}^{-1}$ for the bending vibration of the $\mathrm{CO}$ groups and in the $\cong 600 \mathrm{~cm}^{-1}$ region for the stretching vibration of the $\mathrm{CO}$ group.

In acetic acid, several regions of important bands, such as that of the acetate group in the $2950-2900 \mathrm{~cm}^{-1}$ region and $1430-1380 \mathrm{~cm}^{-1}$ for the $\mathrm{O}-\mathrm{H}$ bond were observed. In the region of $\cong 1725-1700 \mathrm{~cm}^{-1}$ the band was verified referring to the double bond of the group $\mathrm{C}=\mathrm{O}$ and in the region of $1114 \mathrm{~cm}^{-1}$ referring to the $\mathrm{C}-\mathrm{O}$ bond for single bond of carboxyl group. Although several bands of the various characteristics of acetic acid have been detected, one factor that must be taken into account is the impact of the acetic acid in the mixture, since its presence is reduced to a few drops in the $\mathrm{pH}$ adjustment from 7 to 5 . That is, although present, acetic acid did not affect the infrared spectra of the solution used as the solvent.

In the case of silane, the bands were identified in several parts of the infrared spectra. In the $\cong 3700 \mathrm{~cm}^{-1}$ region, there is an intense band indicating the O-H bond, attributed to silanol group, followed by the C-H bonds in the $2970-2900 \mathrm{~cm}^{-1}$ region attributed to alkyl group. In the "fingerprint" region, there are regions in the overlapping infrared spectra, such as in the $\cong 1160 \mathrm{~cm}^{-1}$ region, indicating the connection of siloxanes ( $\mathrm{Si}-\mathrm{O}-\mathrm{Si}$ ) and alkoxy ( $\mathrm{Si}-\mathrm{O}-\mathrm{C}$ ). There is also overlapped bands in the region of $960-900 \mathrm{~cm}^{-1}$, where the band referring to the $\mathrm{C}-\mathrm{O}$ bond of methanol $\left(\cong 1045 \mathrm{~cm}^{-1}\right)$ and water (ranging from 1000 to $550 \mathrm{~cm}^{-1}$ ) may overlap the reference bond to the silanol (Si-OH) of the silane. There is also the possibility of overlapping by the "methanoic" solvent of the bands in the $1045 \mathrm{~cm}^{-1}$ region, referring to the $\equiv \mathrm{Si}-\mathrm{O}-\mathrm{H}$ bond and, also, the bands $802-780 \mathrm{~cm}^{-1}$ referring to the $\mathrm{C}-\mathrm{O}-\mathrm{C}$ bond of the epoxy functional group.

Since the spectra of the concentrated reactants were determined, the spectra of the acidified methanol solutions were analyzed with the silanes in their pure state to verify if it was possible to identify the bands of greatest interest concerning hydrolysis/condensation, which are in the lengths region of $\cong 3700,1200,1160,1045,960-900$ and $880 \mathrm{~cm}^{-1}$, according to presented in Figure 5. 


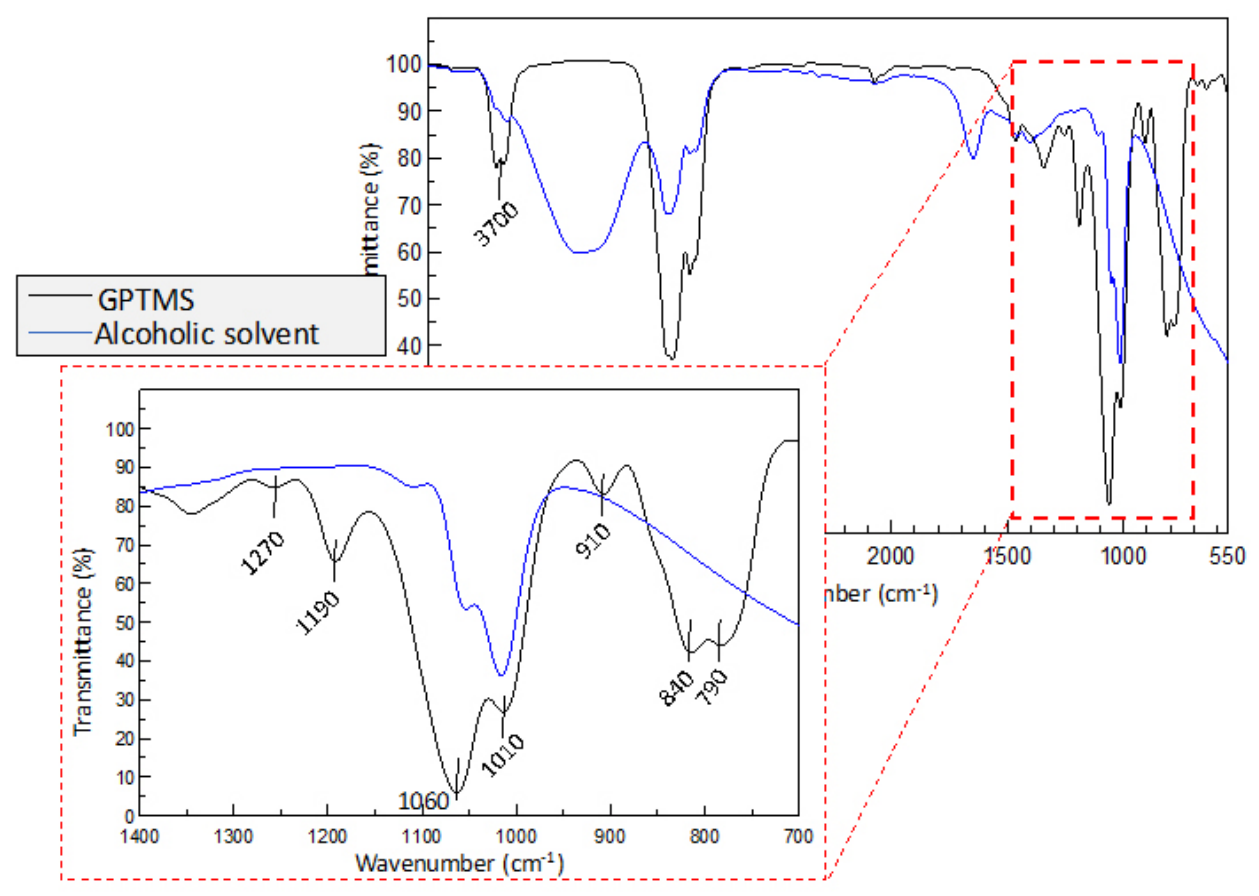

Figure 5: Comparative analysis of the infrared spectra of the methanoic solvent and the concentrated GPTMS infrared spectra.

The GPTMS bands in the $\cong 3700,1200,1160,1045,960-900$ and $800 \mathrm{~cm}^{-1}$ regions were not overlapped by the characteristic bands of the methanoic solution. It was found that there could be identification of hydrolysis/condensation characteristic bands when GPTMS is compared to the methanoic solvent. In the pure silane, the characteristic Si-OH band in the $\cong 3700 \mathrm{~cm}^{-1}$ region was intense, presenting great potential for monitoring. In the region of $\cong 1270 \mathrm{~cm}^{-1}$, the epoxy ring can be monitored and in the region of $1190-1010 \mathrm{~cm}^{-1}$ the condensation reactions of the silane can be monitored by configuring the Si-O-Si bond.

It was found that several bands of the silane overlapped by the reagents of the methanol solution and the silane itself. As an example, the Si-OH bond at the wavelength of $900-960 \mathrm{~cm}^{-1}$ is superimposed by absorption of the bonding corresponding to the epoxy ring in the region of $950-900 \mathrm{~cm}^{-1}$; and in the region of $\cong 3700 \mathrm{~cm}^{-1}$ and $840-780 \mathrm{~cm}^{-1}$ relative to $\mathrm{Si}-\mathrm{OH}$ in the silane GPTMS, there was an overlapping of hydroxyl bands of water and methanol. Despite the possibility of identification of hydrolysis/condensation characteristic bands, because the solutions were composed of significant amounts of solvent (greater than 90\%), 1 and 10\% GPTMS was diluted in the acidified methanol solution in order to verify whether it would be possible to identify the bands of interest.

In Figure 6 the infrared spectra for the concentrated GTPMS and the infrared spectra of the 1\% and 10\% GPTMS solutions are presented. Spectra are shown in the wavelength range of $4000-550 \mathrm{~cm}^{-1}$ and there is also an amplification at $1400-700 \mathrm{~cm}^{-1}$. 


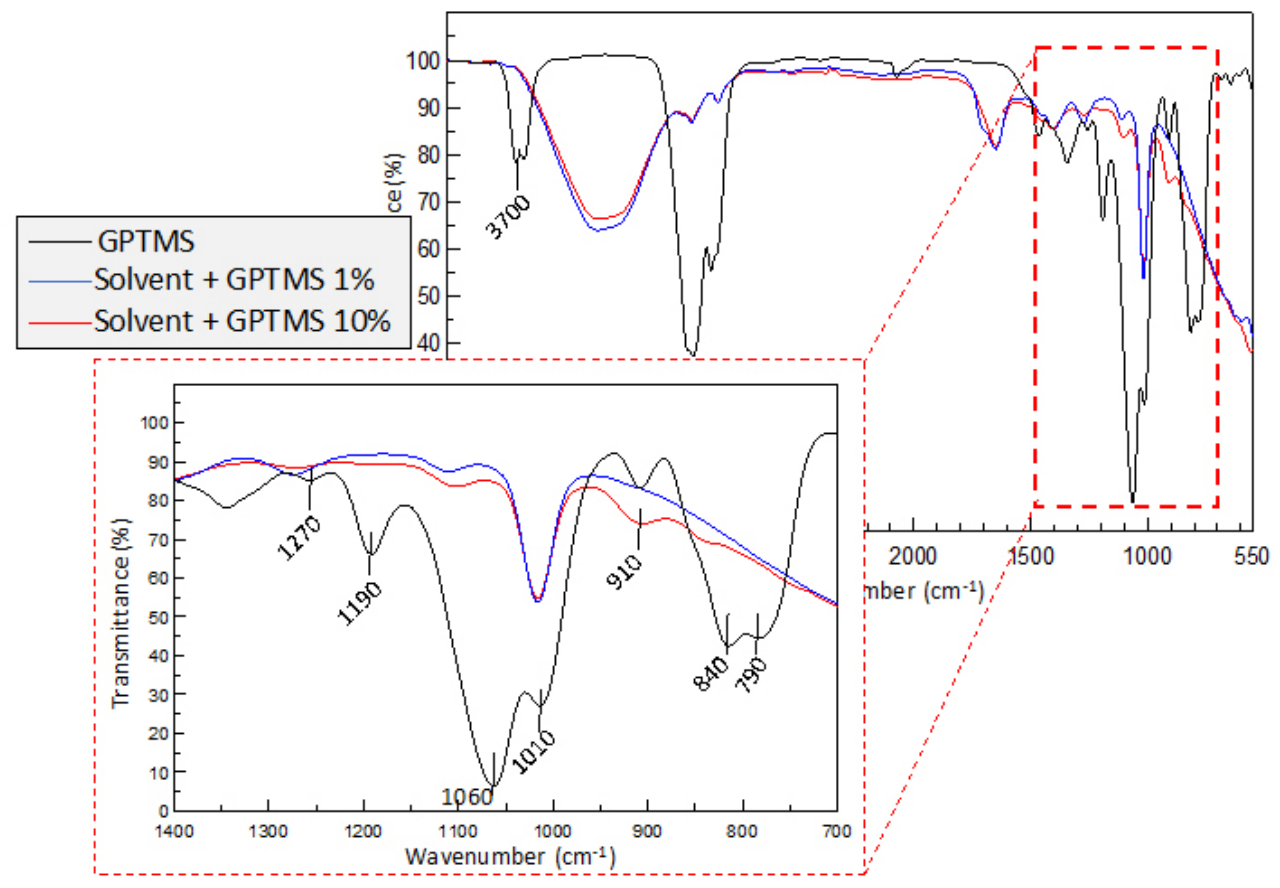

Figure 6: Comparative analysis of the concentrated GPTMS infrared spectra and spectra of solutions with 1 and $10 \%$ concentration of GPTMS.

It has been found that the methanol solvent has a large impact on the infrared spectra of the solution with GPTMS. That is, when silane was added a discrete change over the solvent infrared spectra was observed, especially for the less concentrated solution ( $1 \%$ silane). Nevertheless, it was possible to verify the band around the $910 \mathrm{~cm}^{-1}$, characteristic of silanol $(\mathrm{Si}-\mathrm{OH})$ bonds. However, only when $10 \%$ of GPTMS was used. In this region there was also overlapping of the characteristic bond of the epoxy group. Thus, the region of the $\cong 1270 \mathrm{~cm}^{-1}$ was monitored to confirm if there was change in its intensity (referring to the epoxy) and, thus, to relate its intensity variation with the $\cong 910 \mathrm{~cm}^{-1}$ region.

Although not showing great variation in its intensity, the $3700 \mathrm{~cm}^{-1}$ region, characteristic of Si-OH bonding, was also monitored to be related to the $910 \mathrm{~cm}^{-1}$ region. For practical purposes, as there are bands overlapping, if there is similar variation between these bands, it can be evidenced that the intensity variation in the $910 \mathrm{~cm}^{-1}$ region is related to hydrolysis/ condensation.

At $1100-1000 \mathrm{~cm}^{-1}$, in the $10 \%$ GPTMS solution, higher intensity was observed. This region represents the siloxane bonds and the alkoxy groups. To verify the transmittance variability in this region, bands 1100 and $1020 \mathrm{~cm}^{-1}$ were monitored to identify siloxane formation in the solution. The higher silane concentration in the methanol solvent had the greater possibility of identifying the bands of interest for the hydrolysis/condensation. Therefore, it was decided to use the concentration of $10 \%$ GPTMS diluted in the methanol solvent for the monitoring of hydrolysis/condensation of GPTMS.

\subsection{GPTMS hydrolysis analysis}

In Figure 7 shows the infrared spectra obtained from the dilution of $10 \%$ (vol.) of GPTMS in the methanol solution, using intervals of 10 minute between analyzes, at $4000-550 \mathrm{~cm}^{-1}$. The identification of the hydrolysis time (above the infrared spectra) referred to the extraction of the sample from the moment of dilution of the silane. Details of the bands of interest (with 20 minute intervals) are presented in Figure 8 (a), (b), (c) and (d) for the Si-OH, epoxy, Si-O-Si / Si-OC and Si-OH/ epoxy groups, $\cong 3700,1270,1100,1020$ and $920 \mathrm{~cm}^{-1}$, respectively. 


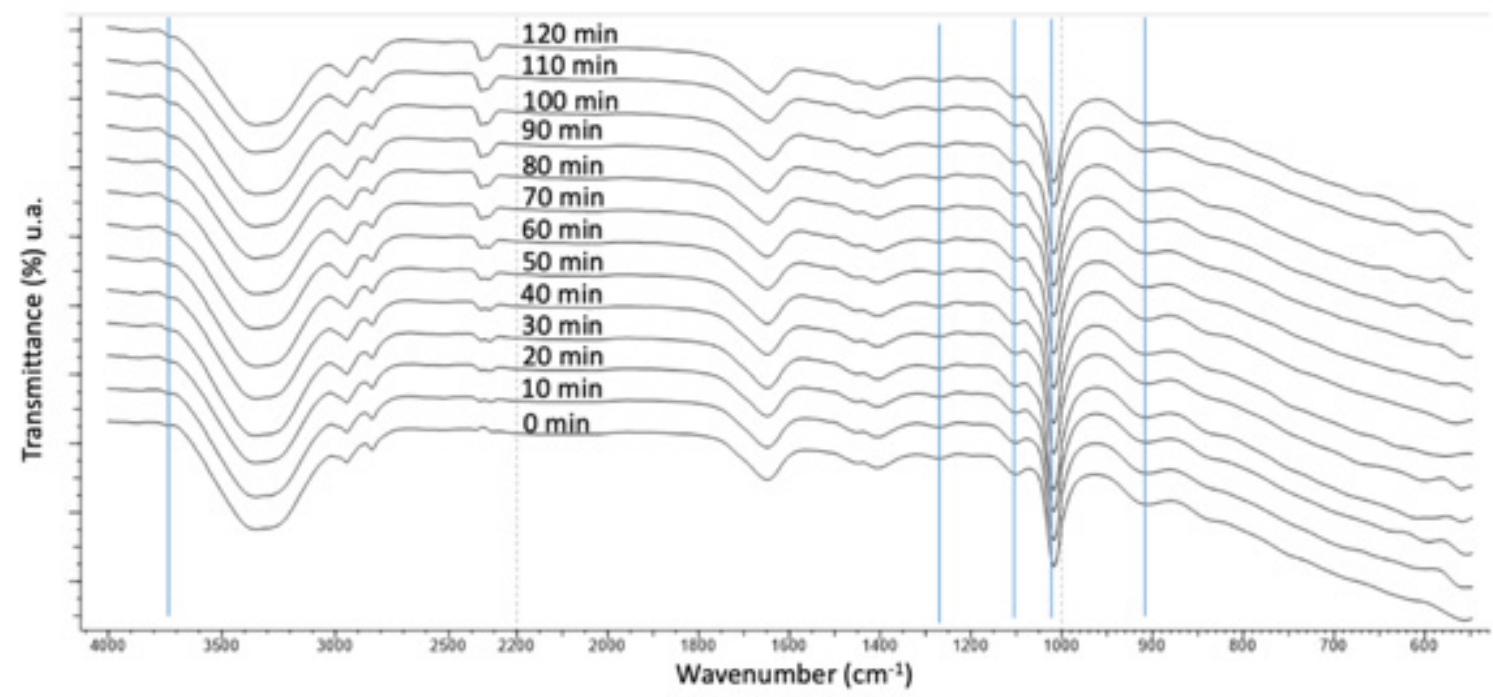

Figure 7: Infrared spectra in the range $4000-550 \mathrm{~cm}^{-1}$; blue bars indicating the wavelengths of $\cong 3700,1270,1100,1020$ and $920 \mathrm{~cm}^{-1}$. Blue lines are guide for the eyes.

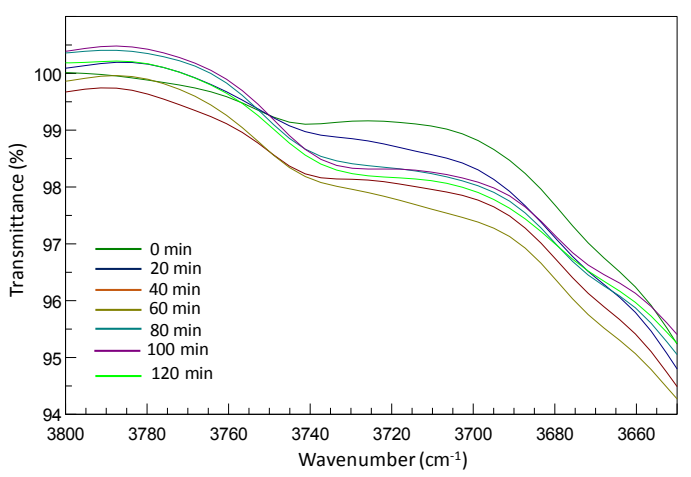

(a)

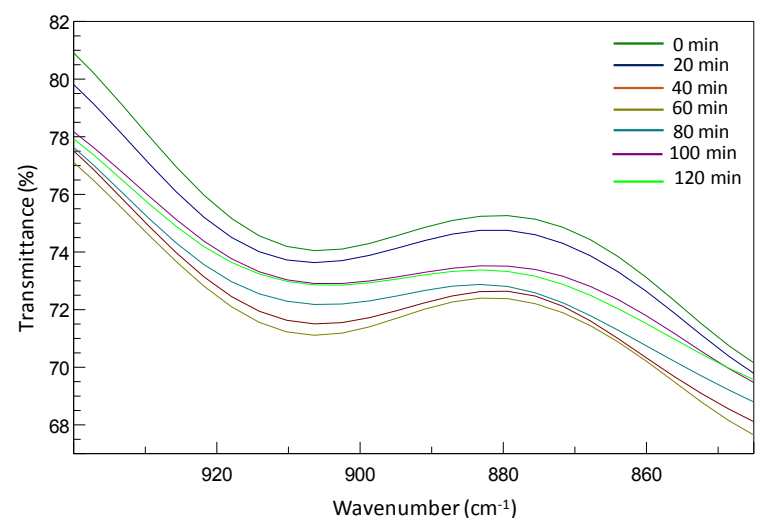

(c)

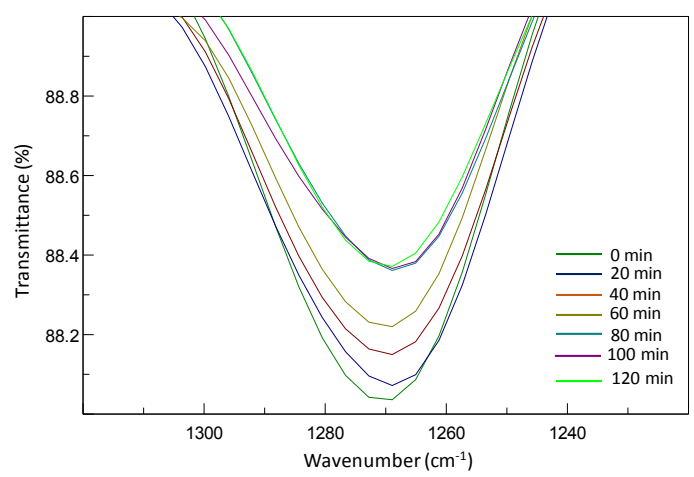

(b)

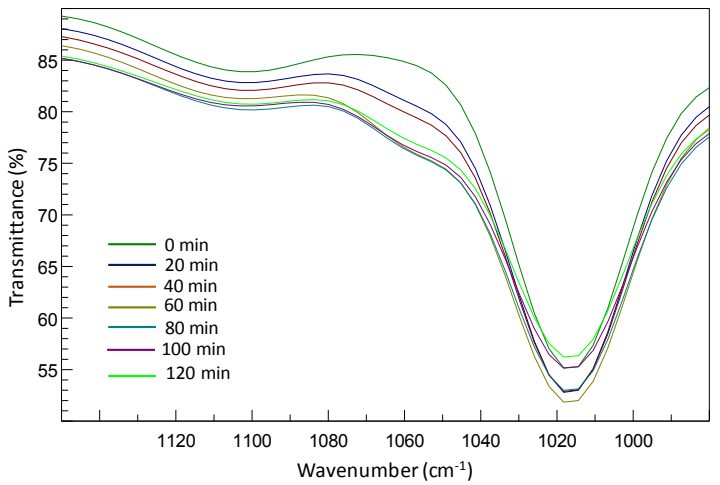

(d)

Figure 8: Bands of the infrared spectra of GPTMS hydrolysis. (a) Si-OH at $\cong 3700 \mathrm{~cm}^{-1}$; (b) Epoxy group at $\cong 1270 \mathrm{~cm}^{-1}$; $\mathrm{Si}-\mathrm{O}-\mathrm{Si} / \mathrm{Si}-\mathrm{O}-\mathrm{C}$ at $\cong 1100 \mathrm{~cm}^{-1}$ and (d) Si-OH$/$ epoxy at $\cong 1020$ and $\cong 920 \mathrm{~cm}^{-1}$.

In Figure 9 are presented, the variation of the transmittance intensity of the selected bands as a function of time, with 10 minute intervals between each GPTMS analysis. 


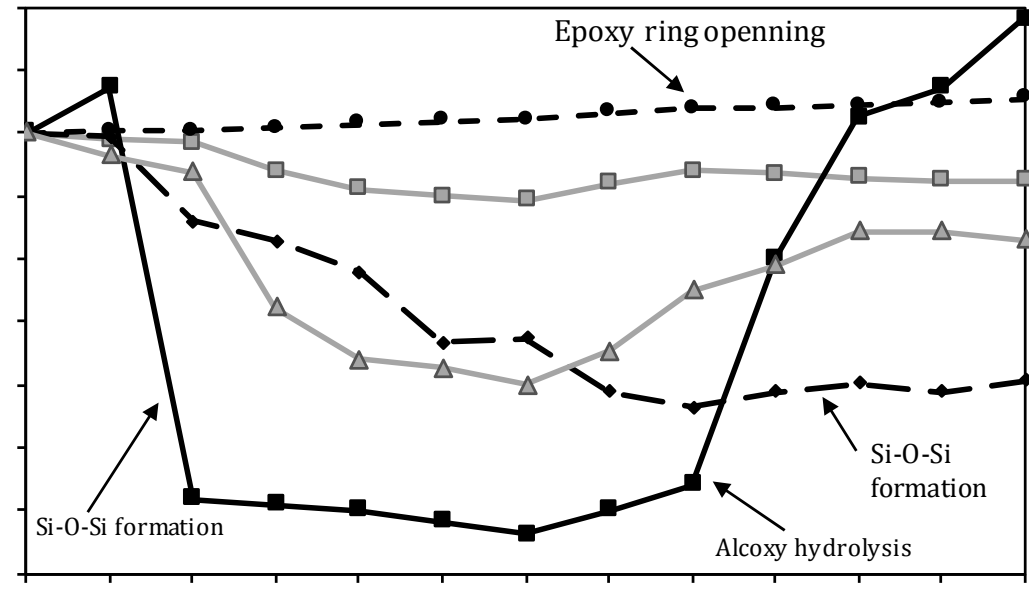

Figure 9: Variation of the transmittance of the bands of interest in the monitoring of GPTMS hydrolysis

In GPTMS, the reaction kinetics are different from that of the alkoxysilanes with four alkoxy groups, as there are only three hydrolysable alkoxy groups, and a faster hydrolysis is expected in relation to the silanes with four hydrolysable groups [14]. In an objective way, the interval of time in which the GPTMS presented greater intensity in the band referring to the silanols groups in the solution was around the 60 minutes.

For the analysis of the GPTMS hydrolysis the band of $\cong 3700 \mathrm{~cm}^{-1}$ was related to the band of $\cong 900 \mathrm{~cm}^{-1}$, both referring to the silanol bond. In parallel, this same band of $900 \mathrm{~cm}^{-1}$ can be related to the band in the region of $\cong 1270 \mathrm{~cm}^{-1}$, referring to the epoxy group.

The bands in the $\cong 3700 \mathrm{~cm}^{-1}$ and $\cong 900 \mathrm{~cm}^{-1}$ regions showed similar behavior in the analyzed period. There was a progressive decrease in the transmittance in the time interval from 20 to 40 minutes until it lowest value in 60 minutes, identifying the highest hydrolysis rate in the period around 30 minutes, which may be due to the progressive hydrolysis of the alkoxy groups. In the case, as it was verified that the transmittance of the characteristic bands of the formation of silanols varied as a function of time, this phenomenon occurred in one alkoxy group at a time, as suggested in the Equation 3 to Equation 5. This conclusion is also suggested by Torry et al. [15]

$$
\begin{aligned}
& \left(\mathrm{CH}_{3}\right)_{3} \mathrm{O}_{3} \mathrm{SiO}_{2} \mathrm{C}_{6} \mathrm{H}_{11}+\mathrm{H}_{2} \mathrm{O} \rightarrow(\mathrm{OH})\left(\mathrm{CH}_{3}\right)_{2} \mathrm{O}_{2} \mathrm{SiO}_{2} \mathrm{C}_{6} \mathrm{H}_{11}+\mathrm{CH}_{3} \mathrm{OH} \\
& (\mathrm{OH})\left(\mathrm{CH}_{3}\right)_{2} \mathrm{O}_{2} \mathrm{SiO}_{2} \mathrm{C}_{6} \mathrm{H}_{11}+\mathrm{H}_{2} \mathrm{O} \rightarrow(\mathrm{OH})_{2} \mathrm{CH}_{3} \mathrm{OSiO}_{2} \mathrm{C}_{6} \mathrm{H}_{11}+\mathrm{CH}_{3} \mathrm{OH} \\
& (\mathrm{OH})_{2} \mathrm{CH}_{3} \mathrm{OSiO}_{2} \mathrm{C}_{6} \mathrm{H}_{11}+\mathrm{H}_{2} \mathrm{O} \rightarrow(\mathrm{OH})_{3} \mathrm{SiO}_{2} \mathrm{C}_{6} \mathrm{H}_{11}+\mathrm{CH}_{3} \mathrm{OH}
\end{aligned}
$$

From 60 minutes, there was a progressive increase in the transmittance value in both regions of the infrared spectra due to the condensation of the silanols and siloxane formation ( $\mathrm{Si}-\mathrm{O}-\mathrm{Si}$ ), indicating that the period in which there is more $\mathrm{Si}-\mathrm{OH}$ presence is around 50 to 60 minutes.

In relation to the epoxy ring, in the region of $\cong 1270 \mathrm{~cm}^{-1}$, it was verified that there was a progressive increase of it transmittance throughout the analyzed period, being able to characterize the ionization by hydrogen or hydroxyl groups on the compound for the formation of groups C-O-H [16], as suggested in the Equation 6.

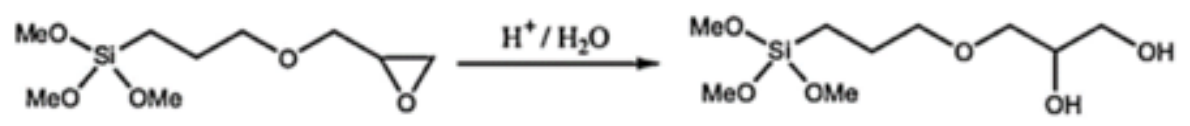

This indicates that it was possible that the epoxy ring presents instabilities in the hydrolysis process of the silane, being able to be hydrolyzed in acidic solutions and to have the ability to react with the surface of substrates and or ions of 
the solution, or even between the groups of hydrolyzed silanes (the main phenomenon of formation of a sol-gel system) [16 - 18]. This also opens up possibilities for polycondensation with the neighboring hydrolyzed molecules by the organic end of the molecule. Thus, it can be stated that the band variation in the $\cong 900 \mathrm{~cm}^{-1}$ region is related to the formation of Si-OH groups, since in the same period the region of $\cong 1270 \mathrm{~cm}^{-1}$ indicates the decrease of the epoxy groups.

The formation of siloxane (Si-O-Si) was monitored by bands at $\cong 1100 \mathrm{~cm}^{-1}$ and $1020 \mathrm{~cm}^{-1}$. In the $\cong 1100 \mathrm{~cm}^{-1}$ band it was observed that there was a progressive reduction of the transmittance, which can be attributed to the condensation of the $\mathrm{Si}-\mathrm{Oh}$ bonds generated in the hydrolysis process of the GPTMS alkoxy groups. For this region of the infrared spectra, the longer the reaction time, the lower this transmittance, until 80 minutes. From the 70 minutes, the reduction in the intensity of the formation of siloxanes and a possible stabilization of the reaction were verified, resulting from the lower availability of silanols over time, as a result of the condensation itself. In parallel, the band in the $\cong 1020 \mathrm{~cm}^{-1}$ region, attributed to overlapping Si-O-Si and Si-OC bonds, showed an abrupt increase in its transmittance immediately after its dilution (up to 10 minutes), which can be attributed to the hydrolysis of the alkoxy groups.

Shortly after, there was a sudden reduction of it transmittance up to 60 minutes, attributed to the condensation of silanols and siloxane formation. In contrast, from 60 minutes, there was an expressive increase in it transmittance. This may be justified by the hydrolysis of the alkoxy groups of the silane, this phenomenon results that the Si-O-C bond, which has a high impact on the infrared spectra, is increasingly less noticeable in it detection region. Thus, in this region of the infrared spectra, despite the reduction of its transmittance by the formation of siloxanes, the absence of alkoxy groups has a much higher impact than the siloxanes, resulting in an increase of transmittance in the analyzed region, thus justifying the increase of its transmittance in parallel with the reduction of the silane hydrolysis rate, around 80 minutes.

\section{CONCLUSIONS}

In this experimental work, GPTMS hydrolysis in alcoholic solutions was monitored by infrared spectroscopic. The results suggest the possibility of using low alcohol solutions for the hydrolysis of GPTMS without damages to the solution, being shown as an alternative to the processes that use high consumption of organic solvents. Hydrolysis/condensation analyzes of the GPTMS allow to trace the "profile" of the hydrolysis/condensation under the conditions studied.

The hydrolysis of GPTMS, in this study, may be divided into three main steps. The first one: from the silane dilution to 20 minutes, where the hydrolysis/condensation can already be detected, but at low intensity; the second: from the 20-60 minutes, where there was an expressive increase in the hydrolysis/condensation reactions and kinetics, reaching the point with the highest number of silanols in 60 minutes and; the third: from the 60 minutes, the kinetics of hydrolysis/condensation of the silane was reduced and the reaction indicates a condensate stabilization.

\section{ACKNOWLEDGMENT}

Authors would like to thank to CAPES (Coordenação de Aperfeiçoamento de Pessoal de Nível Superior) by the scholarship for the first author in the Civil Engineering post-graduate program (PPGEC-UFSC), also by the international scholarship in the project 99999.000243/2015-09. To CNPq and FAPESC for financial support to NanoTec laboratory in the Federal University of Santa Catarina.

\section{BIBLIOGRAPHY}

[1] GUGLIELMI, M., CARTURAN, G., "Precursors for sol-gel preparations", Journal of Non Crystalline Solids, v. 100, pp. 16-30, (1988). doi:10.1016/0022-3093(88)90004-X.

[2] YOUNG, S.K., Overview of Sol-Gel Science and Technology, In: Report ARL-TR-2650, Army Research Laboratory, 2002.

[3] SILVA, A. A., Aerogel de Sílica: Caracterização estrutural e estudo da propriedade da água adsorvida na suaperficie, Tese de D.Sc., Universidade de São Paulo, São Paulo, Brasil, 1992.

[4] COLLODETTI, G., GLEIZE, P.J.P., MONTEIRO, P.J.M., "Exploring the potential of siloxane surface modified nano-SiO2 to improve the Portland cement pastes hydration properties", Construction and Building Materials, v. 54, pp. 99-105, 2014. doi:10.1016/j.conbuildmat.2013.12.028.

[5] LENZA, R.F.S., VASCONCELOS, W.L., "Síntese de membranas cerâmicas via método sol-gel utilizando TEOS e N,N-dimetilformamida”, Química Nova, v. 25, pp. 893-896, 2002. doi:10.1590/S0100-40422002000600002. 
[6] SINGH, L.P., BHATTACHARYYA, S.K., KUMAR, R., et al. "Sol-Gel processing of silica nanoparticles and their applications", Advances in Colloid and Interface Science, v.214, pp. 17-37, 2014. doi:10.1016/j.cis.2014.10.007.

[7] LUO, W., ZHAO, L., "The influence of GPTMS on the performance of silica-ionic liquid hybrid membrane”, Solid State Ionics, v. 268, pp. 94-101, 2014. doi:10.1016/j.ssi.2014.10.003.

[8] SINGH, L.P., ALI, D., SHARMA, U., "Studies on optimization of silica nanoparticles dosage in cementitious system", Cement and Concrete Composites, v. 70, pp. 60-68, 2016. doi:10.1016/j.cemconcomp.2016.03.006.

[9] LONGHI, M., KUNSTA, S.R., BELTRAMI, L.V.R., et al.“Effect of Tetraethoxy-silane (TEOS) Amounts on the Corrosion Prevention Properties of Siloxane-PMMA Hybrid Coatings on Galvanized Steel Substrates”, Materials Research, v. 18 pp. 1140-1155, 2015. doi:10.1590/1516-1439.321614.

[10] CASAGRANDE, C.A., CAVALARO, S.H.P., REPETTE, W.L., "Ultra-high performance fibre-reinforced cementitious composite with steel microfibres functionalized with silane", Construction and Building Materials, v. 178, pp. 495506, 2018. doi:10.1016/j.conbuildmat.2018.05.167.

[11] TÉLLEZ, L., RUBIO, F., PEÑA-ALONSO, R., et al."Seguimiento por espectroscopia infrarroja (FT-IR) de la copolimerización de TEOS (tetraetilortosilicato) y PDMS (polidimetilsiloxano) en presencia de tbt (tetrabutiltitanio)", Boletín de la Sociedad Española de Cerámica y Vidrio, v.43, pp. 883-890, 2004. doi:10.3989 /cyv.2004.v43.i5.

[12] CASAGRANDE, C.A., REPETTE, W.L., "Monitoramento da hidrólise/condensação do tetraetoxisilano em solução com baixo teor alcoólico por análises de espectroscopia de infravermelho", Matéria (Rio Janeiro). v. 23, n. 4, 2018. doi:10.1590/s1517-707620180004.0571.

[13] CASAGRANDE, C.A., Desempenho de microfibras de aço funcionalizadas com silanos em Concreto de Ultra-Alto Desempenho Reforçado com Fibras, Tese de D.Sc, Universidade Federal de Santa Catarina, Florianópolis, SC, Brasil, 2017. http://tede.ufsc.br/teses/PECV1073-T.pdf.

[14] ARKLES, B., STEINMETZ, J.R., ZAZYCZNY, J., et al."Factors contributing to the stability of alkoxysilanes in aqueous solution", Journal of Adhesion Science and Technology, v. 6, pp. 193-206, 1996. doi:10.1163/156856192X00133.

[15] TORRY, S. A., CAMPBEL, A., CUNLIFFE, A. V., et al."Kinetic analysis of organosilane hydrolysis and condensation”, International Journal of Adhesion and Adhesives, v. 26 pp. 40-49, 2006. doi:10.1016/j.ijadhadh.2005.03.008.

[16] ALOTHMAN, Z.A., APBLETT, A.W., "Preparation of mesoporous silica with grafted chelating agents for uptake of metal ions”, Chemical Engineering Journal, v. 155, pp. 916-924, 2009. doi:10.1016/j.cej.2009.09.028.

[17] CHRUŚCIEL, J.J., LEŚNIAK, E., "Modification of epoxy resins with functional silanes, polysiloxanes, silsesquioxanes, silica and silicates", Progress in Polymer Science, v. 41, pp. 67-121, 2014. doi:10.1016/j.progpolymsci.2014.08.001.

[18] INNOCENZI, P., FIGUS, C., KIDCHOB, T., et al."Crystallization in hybrid organic-inorganic materials through self-organization from 3-glycidoxypropyltrimethoxysilane", Journal of the Ceramic Society of Japan, v. 119, pp. 387-392, 2011. doi:10.2109/jcersj2.119.387.

\section{ORCID}

Cézar Augusto Casagrande Lidiane Fernanda Jochem Wellington Longuini Repette http://orcid.org/0000-0002-4293-6574

https://orcid.org/0000-0001-6679-2897 http://lattes.cnpq.br/6714147994303668 